Prepared in cooperation with the DuPage County Stormwater Management Department

\title{
Full Equations Model Graphical Data Inspector (FE0-GDI) User Guide
}

Open-File Report 2019-1113 



\section{Full Equations Model Graphical Data Inspector (FEQ-GDI) User Guide}

By Jessica L. Ern, Terry Ortel, Audrey L. Ishii, and Maitreyee Bera

Prepared in cooperation with the DuPage County Stormwater Management Department

Open-File Report 2019-1113 


\title{
U.S. Department of the Interior DAVID BERNHARDT, Secretary
}

\author{
U.S. Geological Survey \\ James F. Reilly II, Director
}

U.S. Geological Survey, Reston, Virginia: 2019

For more information on the USGS - the Federal source for science about the Earth, its natural and living resources, natural hazards, and the environment-visit https://www.usgs.gov or call 1-888-ASK-USGS.

For an overview of USGS information products, including maps, imagery, and publications, visit https://store.usgs.gov.

Any use of trade, firm, or product names is for descriptive purposes only and does not imply endorsement by the U.S. Government.

Although this information product, for the most part, is in the public domain, it also may contain copyrighted materials as noted in the text. Permission to reproduce copyrighted items must be secured from the copyright owner.

Suggested citation:

Ern, J.L., Ortel, T., Ishii, A.L., and Bera, M., 2019, Full Equations Model Graphical Data Inspector (FEQ-GDI) user guide: U.S. Geological Survey Open-File Report 2019-1113, 11 p., https://doi.org/10.3133/ofr20191113.

ISSN 2331-1258 (online) 


\section{Contents}

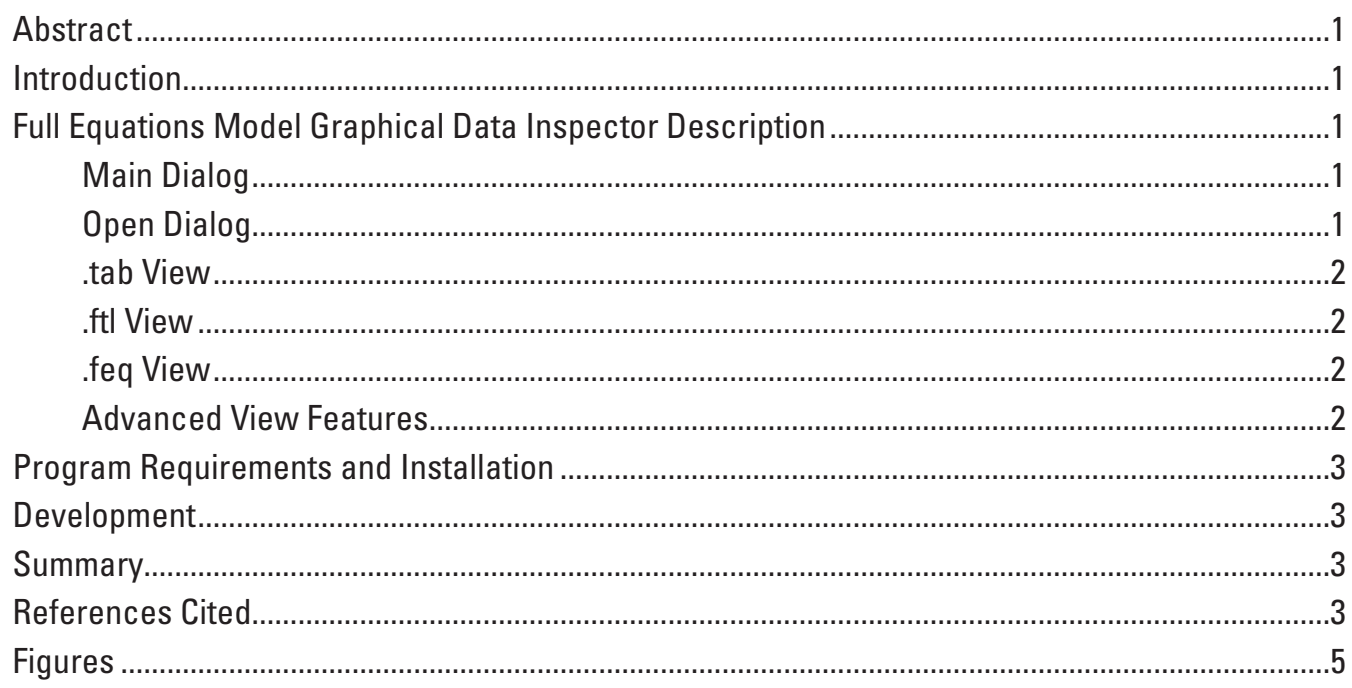

\section{Figures}

1. Screenshots showing, $A$, the Main Dialog and, $B$, the Open Dialog for selecting

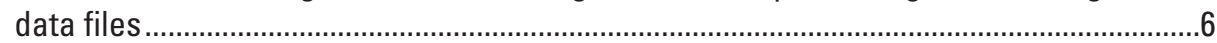

2. Screenshots showing plots generated by the tab views...................................................7

3. Screenshot showing Manning's roughness coefficients and a selected point.................8

4. Screenshot showing a culvert structure with Manning's roughness coefficients ...........8

5. Screenshot showing a plot generated by the feq view ....................................................

6. Screenshot showing Show Branch Numbers enabled ........................................................

7. Screenshot showing Show Nodes and Branches enabled ..........................................10

8. Screenshots showing, $A$, the Annotations drop-down menu and, $B$, text entered

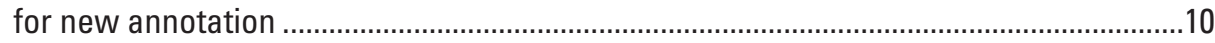

9. Screenshot showing new annotation on the chart ......................................................11

10. Screenshot showing the context menu ......................................................................11

11. Screenshot showing the Chart Properties menu ..........................................................11 


\section{Abbreviations}

FE0 Full Equations

FEQ-GDI Full Equations Model Graphical Data Inspector

FEQUTL Full Equations Utilities Program 


\title{
Full Equations Model Graphical Data Inspector (FEQ-GDI) User Guide
}

\author{
By Jessica L. Ern, ${ }^{1}$ Terry Ortel, ${ }^{2}$ Audrey L. Ishii, ${ }^{3}$ and Maitreyee Bera ${ }^{2}$
}

\begin{abstract}
The Full Equations Model Graphical Data Inspector (FEQ-GDI) is a menu-driven utility program that enables users to visualize and check the geometric and hydraulic properties of channel cross sections, selected control structures, and stream profiles in the input files for the Full Equations (FEQ) Model and the Full Equations Utilities (FEQUTL) Model. The FEQ Model is a computer program for the simulation of one-dimensional, unsteady flow in open channels and through control structures using the full, dynamic equations of motion. The input to FEQ Model includes the output from the FEQUTL Model, which computes tables relating the hydraulic properties of channel cross sections and control structures to depth, flow, and (or) other specified parameters. FEQ-GDI can be used to help users quickly detect anomalies in the data that may indicate errors in the input files.
\end{abstract}

\section{Introduction}

The Full Equations Model Graphical Data Inspector (FEQ-GDI) is a utility program that enables users to visualize and check the geometric and hydraulic properties of channel cross sections, selected control structures, and stream profiles, which helps users quickly detect anomalies in the data that may indicate errors in the input files for the Full Equations (FEQ) modeling system. FEQ is a computer program used to simulate one-dimensional, unsteady flow in open channels and through control structures using the full, dynamic equations of motion (Franz and Melching, 1997a). The input to FEQ includes the output from the Full Equations Utilities Program (FEQUTL), which computes tables relating the hydraulic properties of channel cross sections and control structures to depth, flow, other specified parameters, or all the above (Franz and Melching, 1997b).

${ }^{1}$ Student, U.S. Geological Survey. Work was done while employed by the U.S. Geological Survey.

${ }^{2}$ U.S. Geological Survey.

${ }^{3}$ Retired, U.S. Geological Survey. Work was done while employed by the U.S. Geological Survey.
This report describes FEQ-GDI, a menu-driven utility program designed to graphically represent fixed-column width files used in FEQ simulation. These files include the input and output of FEQUTL. FEQ-GDI reads the FEQUTL input files containing geometric and hydraulic data that are designated by the .ftl extension and the output files of hydraulic properties that are designated by the tab extension. The FEQ input file, designated by the .feq or .in extension, must contain the station and elevation data that describe the stream profile for it to be an input to FEQ-GDI. More information on FEQ and FEQUTL is available at https://water.usgs.gov/software/feq.

\section{Full Equations Model Graphical Data Inspector Description}

\section{Main Dialog}

Opening the FEQ-GDI utility program brings up the Main Dialog (fig. 1A), which contains a File drop-down menu, an About button, a Help button, an area that contains a list of viewable data files, and a View Data button. The File drop-down menu provides two options to the user: Open and Exit. Open brings up the Open Dialog, allowing the user to select and open data files (fig. $1 B$ ), and Exit closes the program. The About button brings up an alert box that contains information about the current version of the program and the documentation. The Help button brings up a dialog with a list of common errors and advice on fixing them.

\section{Open Dialog}

In the Open Dialog (fig. 1B), users can click on the Add button to bring up the File Chooser Dialog. From there, users can select a file or multiple files to add to the File List. Once added to the list, files can be selected and removed with the Remove button. Multiple files can be selected by holding down the Ctrl or Shift key. Once the user finishes selecting files, the $\mathbf{O K}$ button can be clicked, and then file contents will be parsed and displayed in the Main Dialog list (fig. 1A). 
Each item shows the filename that the data was parsed from and the name of the item (fig. 1A). For the data file with the feq extension, the name of the item and filename are the same. The list can be reordered by clicking the list headers. For the data files with .ftl and tab extensions, the name is a combination of the TAB or TABLE identification number and the command (for example FEQX and CULVERT) for that item. Two checkboxes indicate whether the source file was with .tab, ftt, or both extensions. If neither option is checked, the source file was an FEQ file with the .feq or .in extension.

To view the graphs of the plotted data, a user will select an item on the list and click the View Data button. This will bring up viewing windows for the .tab .ftl or .feq input data file, depending on which item is selected. Opening an item will open all views for that item at the same time.

\section{.tab View}

The tab file view consists of a line graph showing the data in each column at various depths. The lower part of the window is a scrollable table that lists all the data that were parsed for the selected cross section. The columns to display in the graph can be selected with the checkboxes at the bottom of the window, as shown in figure $2 A$ and $2 B$. The Print Table button next to the checkboxes will print an image of the table in its entirety.

\section{.ftl View}

The $\mathrm{ftl}$ file view consists of a two-dimensional $\mathrm{X}-\mathrm{Y}$ plot of the selected cross section (FEQX) or control structures (CULVERT or MULCON). The user can select the Show N Values radio button to display the Manning's roughness coefficients ( $n$-values) corresponding to the cross-section segments (fig. 3). Clicking on a data point will turn the data point from red to blue (as in fig. 3) and display the information associated with that point at the bottom of the window including its $\mathrm{X}$ and $\mathrm{Y}$ coordinates, its associated $n$-value (FEQX) or width value (CULVERT), and any notes that were in the ftt file (fig. 3). Clicking on an empty part of the plot will deselect the point.

In control structures, the culvert shapes (MULCON or CULVERT) are drawn on the graph in black and labeled with their $n$-values if it is available in the .ftl file (fig. 4). If no coordinates are available in the ftl file, it will be centered at the lowest point of the stream cross section.

\section{.feq View}

The .feq file view has an initially blank two-dimensional $\mathrm{X}-\mathrm{Y}$ Plot and a table listing the FEQ input branches found in the file. If a branch was not read in properly, "ERROR" will be printed in the third column of the table next to the branch. Clicking on a data point will display the associated branch number, its $\mathrm{X}$ and $\mathrm{Y}$ coordinates, its XNUM name, and a note consisting of its NODE and NodeId if they were found for that point (fig. 5). Clicking on an empty part of the plot will deselect the point.

Clicking a branch or selecting multiple branches in the table will toggle whether or not the branch stream profile is displayed in the chart. The column of checkboxes indicates if a branch is currently in the chart. If there is an error in the branch, its checkbox cannot be checked. To toggle all the branches at once, click the column header over the checkboxes. Clicking the Branch header will reverse the order that the branches are listed.

Selecting the Show Branch Numbers radio button will display the branch numbers over the branches in the chart (fig. 6). Selecting the Show Nodes and Branches radio button will differentiate the branches with colored lines and distinct data-point markers and make the data points larger and easier to click (fig. 7).

\section{Advanced View Features}

In the drop-down menu labeled "Annotations" at the top of the .ftl file view and .feq file view windows (figs. 3-8A) the user can add their own annotations to the chart. The Annotations drop-down menu provides three options to the user: New, Clear Previous, and Clear All (fig. 8A). Selecting New will bring up a dialog box where the annotation text will be entered (fig. 8B). After entering the text, the user can click anywhere on the chart to place the annotation (fig. 9). Clear Previous allows the user to choose to delete the last annotation made and Clear All allows the user to choose to delete all annotations.

Because FEQ-GDI uses the JFreeChart library (http:// www.jfree.org/jfreechart/) to plot its data, it has inherited several advanced features for manipulating these graphs.

The graph can be zoomed by dragging a box around an area with the left mouse button. Dragging a box from top left to bottom right will zoom in to the section covered by the box, whereas attempting to create a box by dragging any other direction resets the zoom to view all data points. Other options for zooming in and out are available in the context menu (fig. 10) by right clicking anywhere on the plot. Users have the option of manually zooming either axis, or they can choose the "Auto Range" option that will fit the plot to the data points automatically.

Additional options are available from the context menu. Chart colors and appearance can be changed by choosing Properties (fig. 11). The graph image can be copied to the clipboard by choosing Copy. The image can also be saved to a file by choosing Save as. Finally, you can print out the image by choosing Print. 


\section{Program Requirements and Installation Summary}

The FEQ-GDI was written in Java and requires that Java 1.7 or higher is installed on the machine that the program will be run on. The program does not include an installer and can simply be run by unzipping the distributed archive and executing the FEQ-GDI.jar file inside. FEQ-GDI can also be run from the command line using "java -jar FEQ-GDI.jar" and can be followed by a space separated list of files to initialize the table with.

FEQ-GDI supports .ftl files with the commands FEQX, CULVERT, and MULCON, tab files with tables of the types 20 through 25 , and the .feq and in files with BNUM data blocks (Franz and Melching, 1997a) containing numerical values for station and elevation. If any of the files passed into FEQ-GDI do not adhere to fixed column width formatting they may not be parsed correctly.

The FEQ-GDI application is provided as an executable file format for the ease of the user. The executable file is available for download at https://il.water.usgs.gov/proj/feq/ software/feqgdi.

\section{Development}

The application was developed entirely in Java. The Java Swing GUI toolkit and the WindowBuilder plugin for Eclipse were used to create most of the graphical controls and components. The open-source framework, JFreeChart, was used for rendering all the charts that the application currently (2019) supports. All automated testing has been done with unit testing framework, JUnit, and the Java editor, Eclipse.
The Full Equations Model Graphical Data Inspector (FEQ-GDI) is a menu-driven utility program that enables users to visualize and check the geometric and hydraulic properties of channel cross sections, selected control structures, and stream profiles, helping users quickly detect anomalies in the data that may indicate errors in the input files for the Full Equations (FEQ) Model. The input to the FEQ Model includes the output from the Full Equations Utilities (FEQUTL) Model, which computes tables relating the hydraulic properties of channel cross sections and control structures to depth, flow, and (or) other specified parameters. FEQ-GDI reads the fixed column-width formatted input files used by the FEQ and FEQUTL Models and may not correctly parse other input formats.

\section{References Cited}

Franz, D.D., and Melching, C.S., 1997a, Full Equations (FEQ) model for the solution of the full, dynamic equations of motion for one-dimensional unsteady flow in open channels and through control structures: U.S. Geological Survey Water-Resources Investigations Report 96-4240, 258 p., accessed August 2019 at https://doi.org/10.3133/wri964240.

Franz, D.D., and Melching, C.S., 1997b, Full Equations Utilities (FEQUTL) model for the approximation of hydraulic characteristics of open channels and control structures during unsteady flow: U.S. Geological Survey Water-Resources Investigations Report 97-4037, 205 p., accessed August 2019 at https://doi.org/10.3133/wri974037. 

Figures 
A

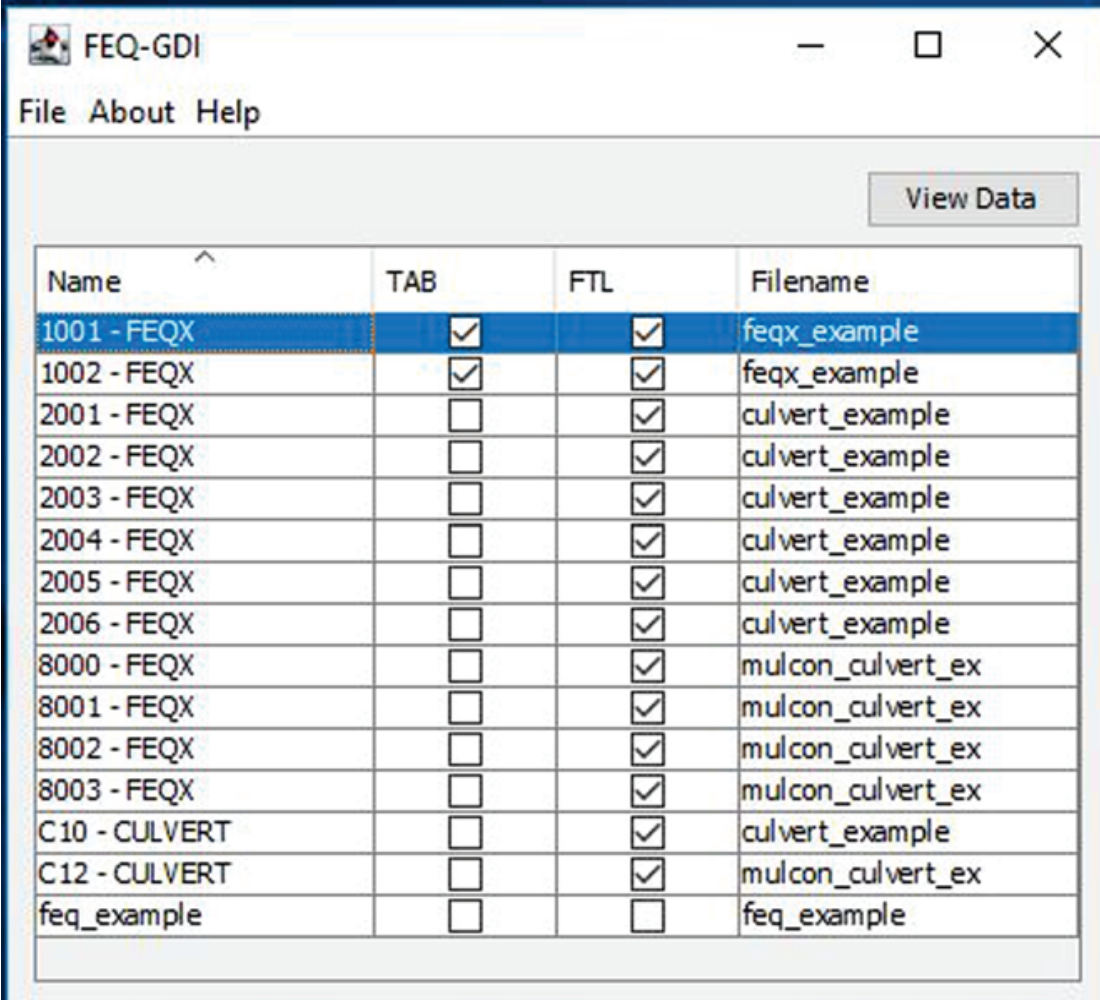

B

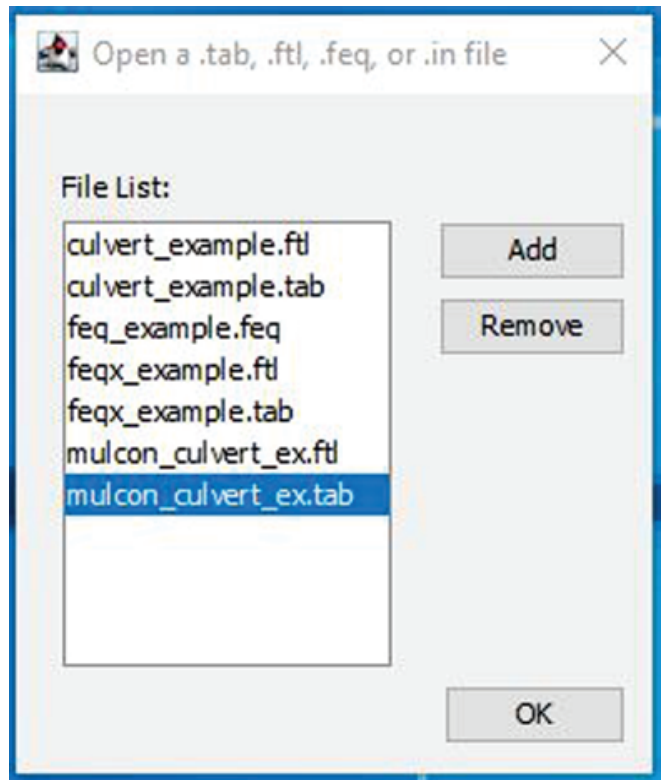

Figure 1. Screenshots showing, $A$, the Main Dialog and, $B$, the Open Dialog for selecting data files 
A

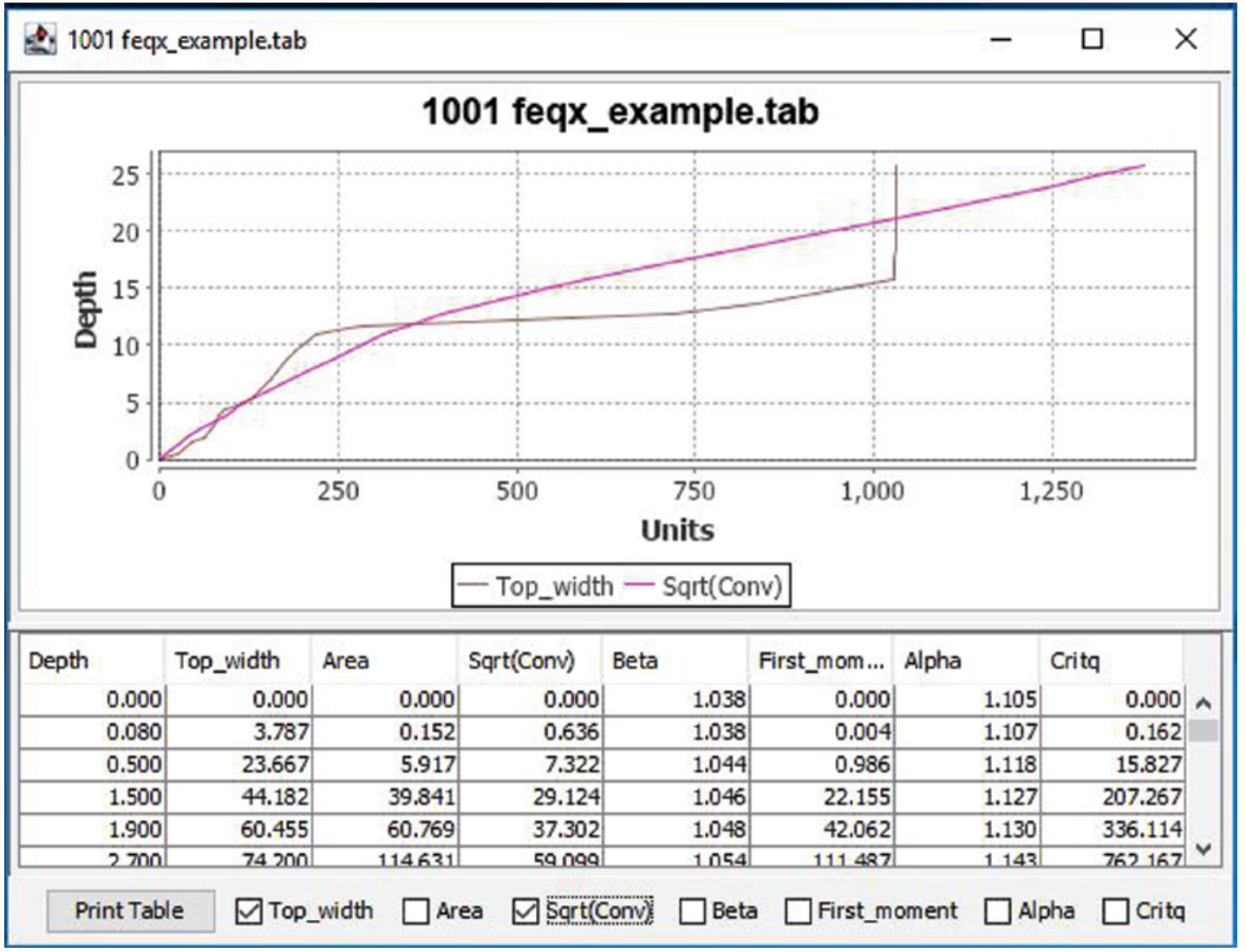

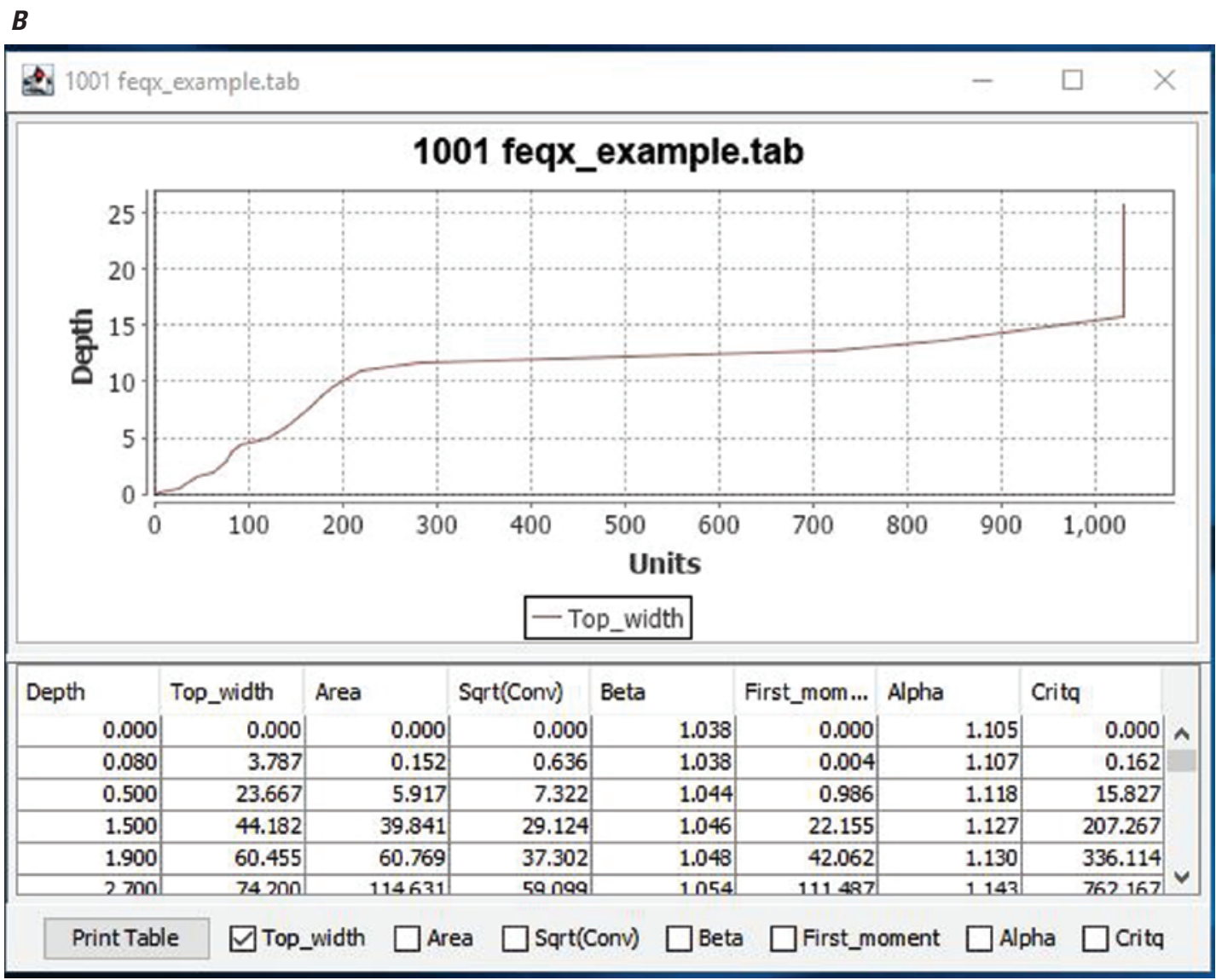

Figure 2. Screenshots showing plots generated by the tab views. $A$, two boxes checked and, $B$, one box checked. 


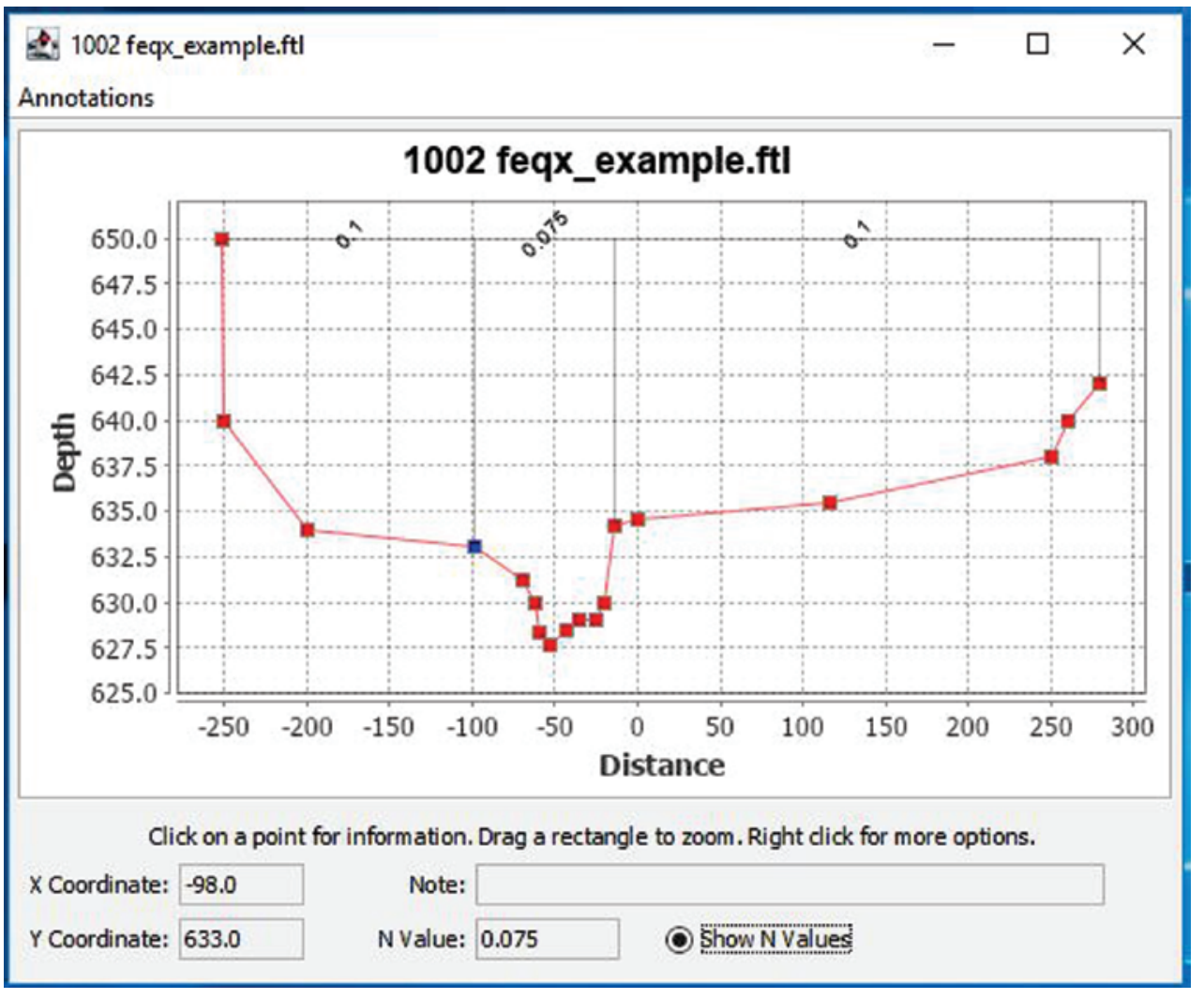

Figure 3. Screenshot showing Manning's roughness coefficients ( $n$-values) and a selected point.

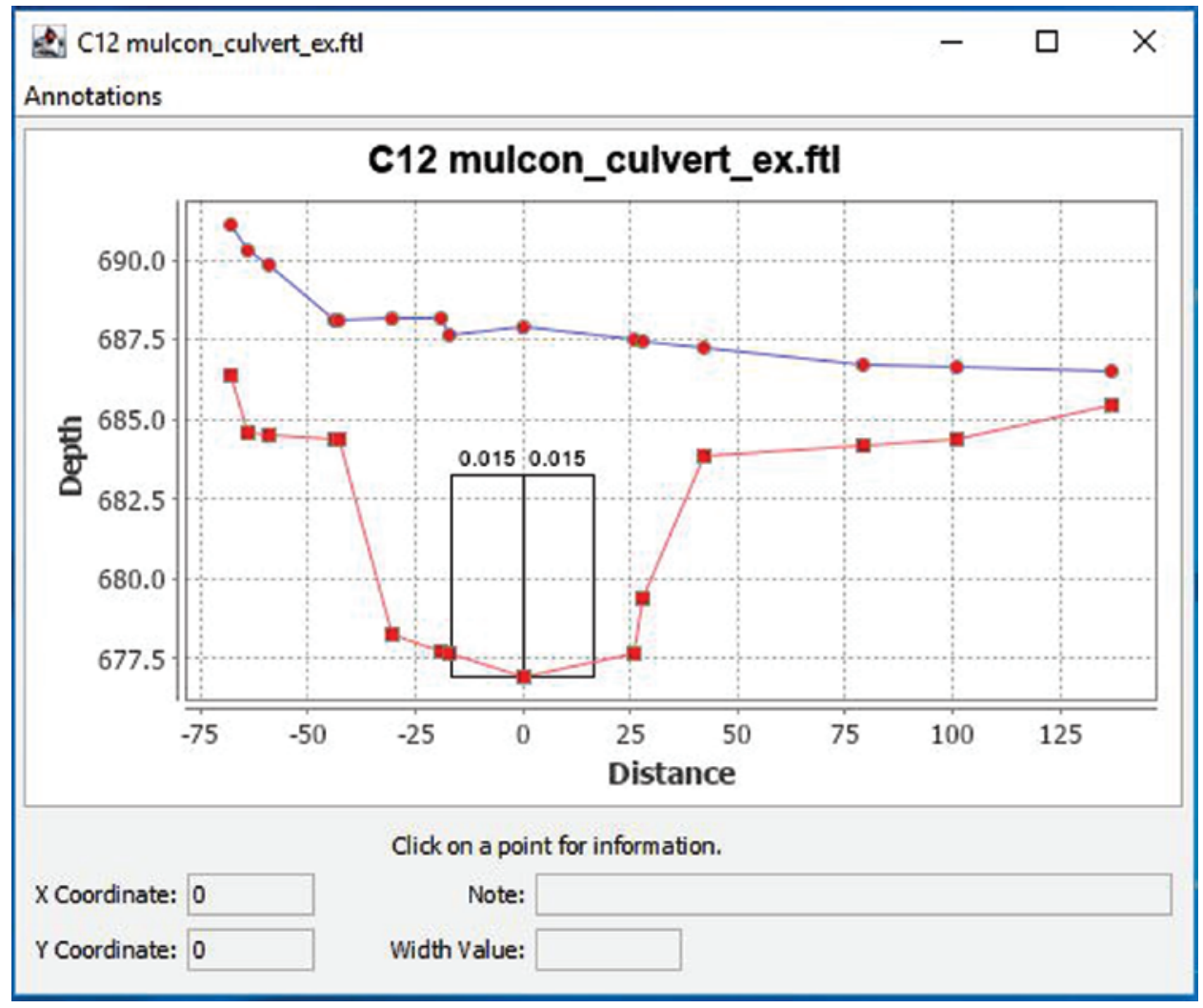

Figure 4. Screenshot showing a culvert structure with Manning's roughness coefficients ( $n$-values). 


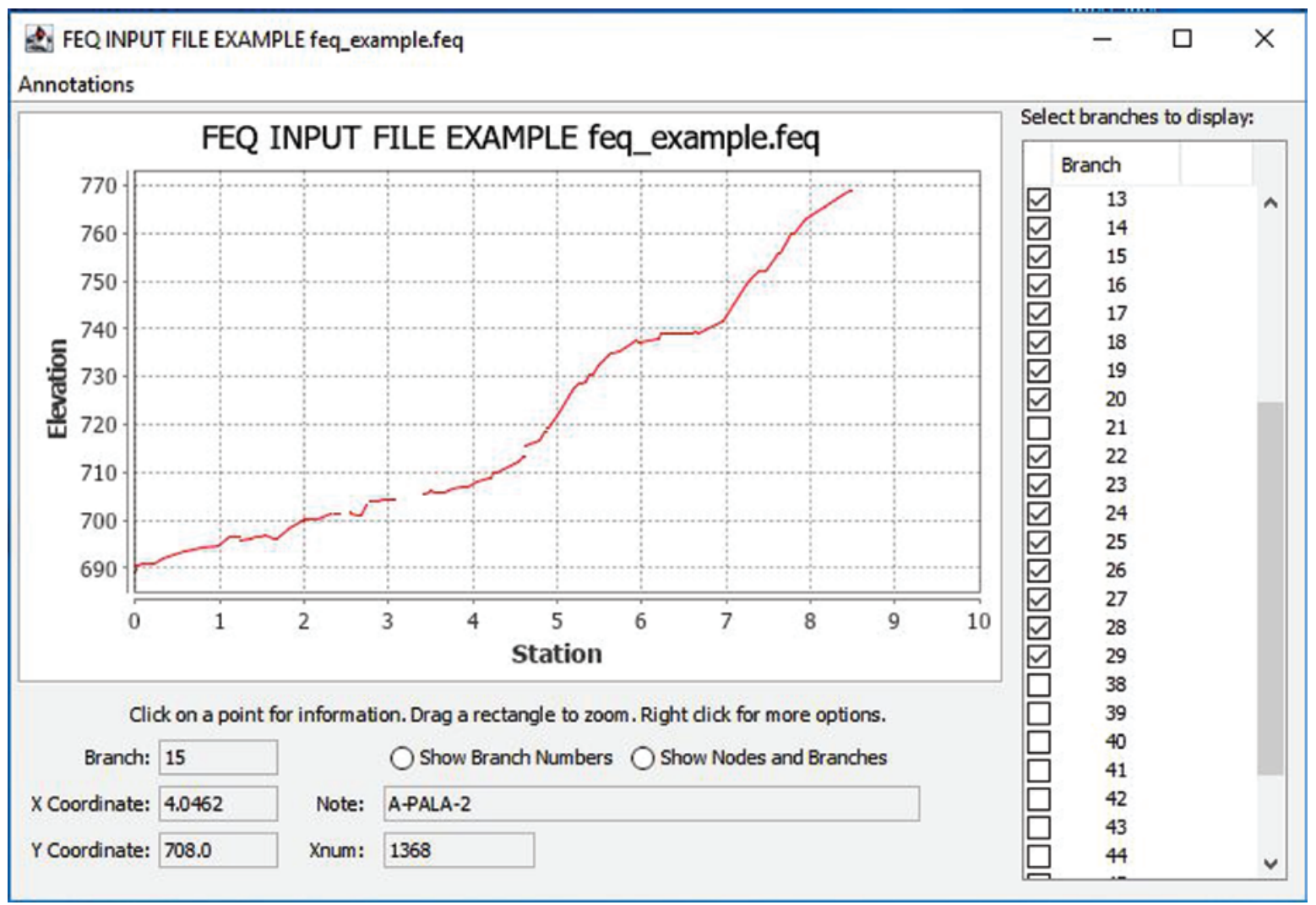

Figure 5. Screenshot showing a plot generated by the feq view.

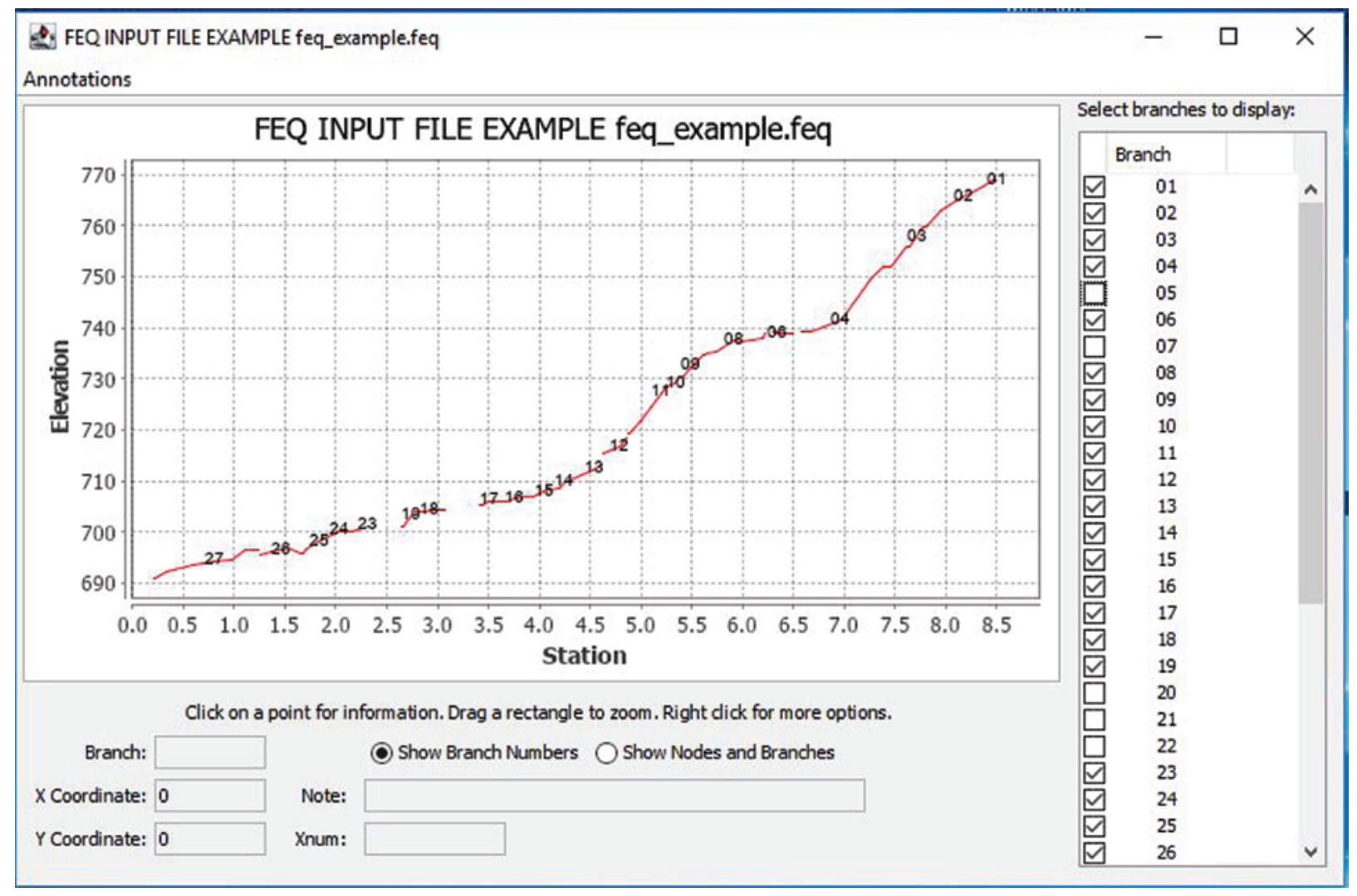

Figure 6. Screenshot showing Show Branch Numbers enabled. 


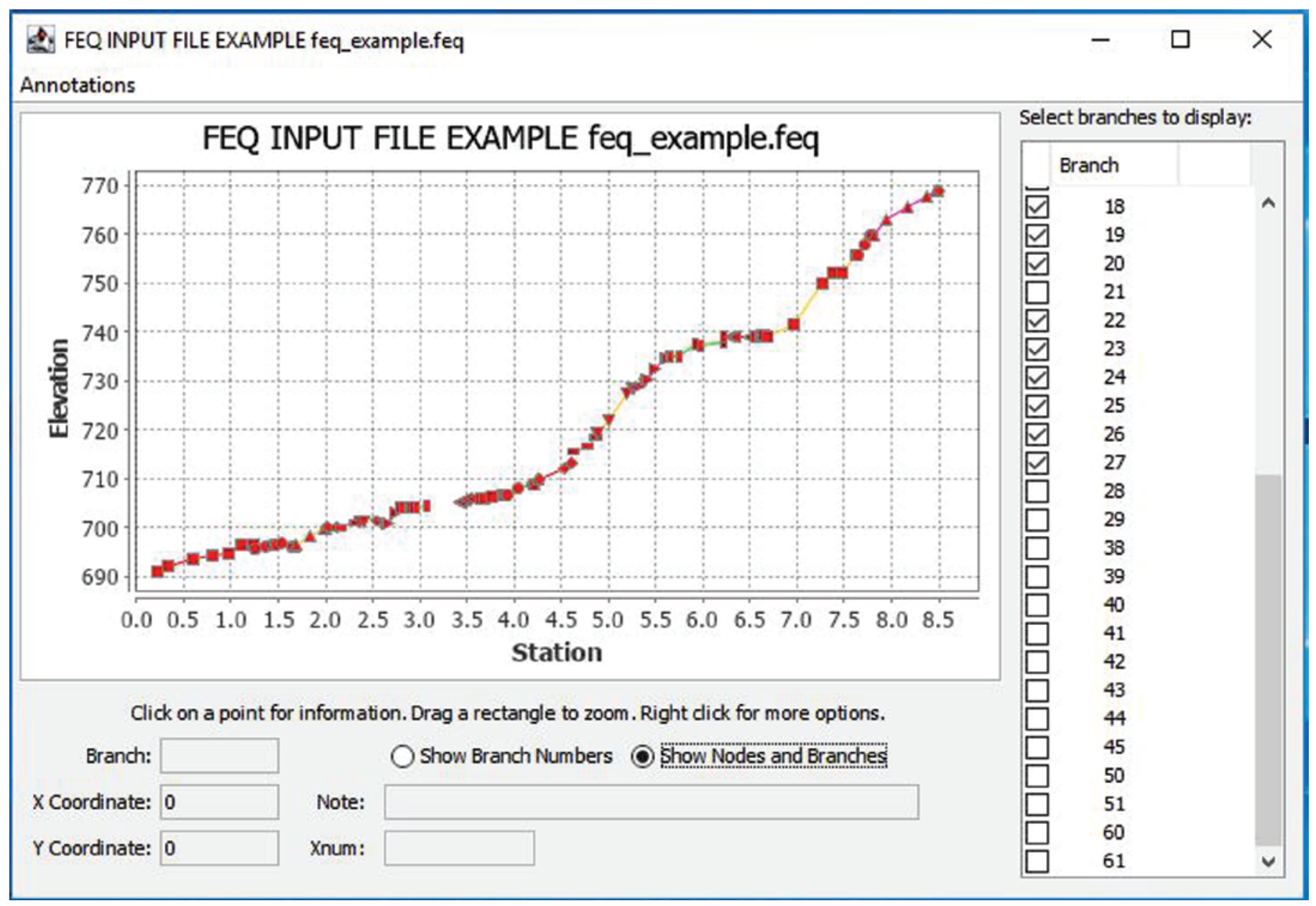

Figure 7. Screenshot showing Show Nodes and Branches enabled.

$\boldsymbol{A}$

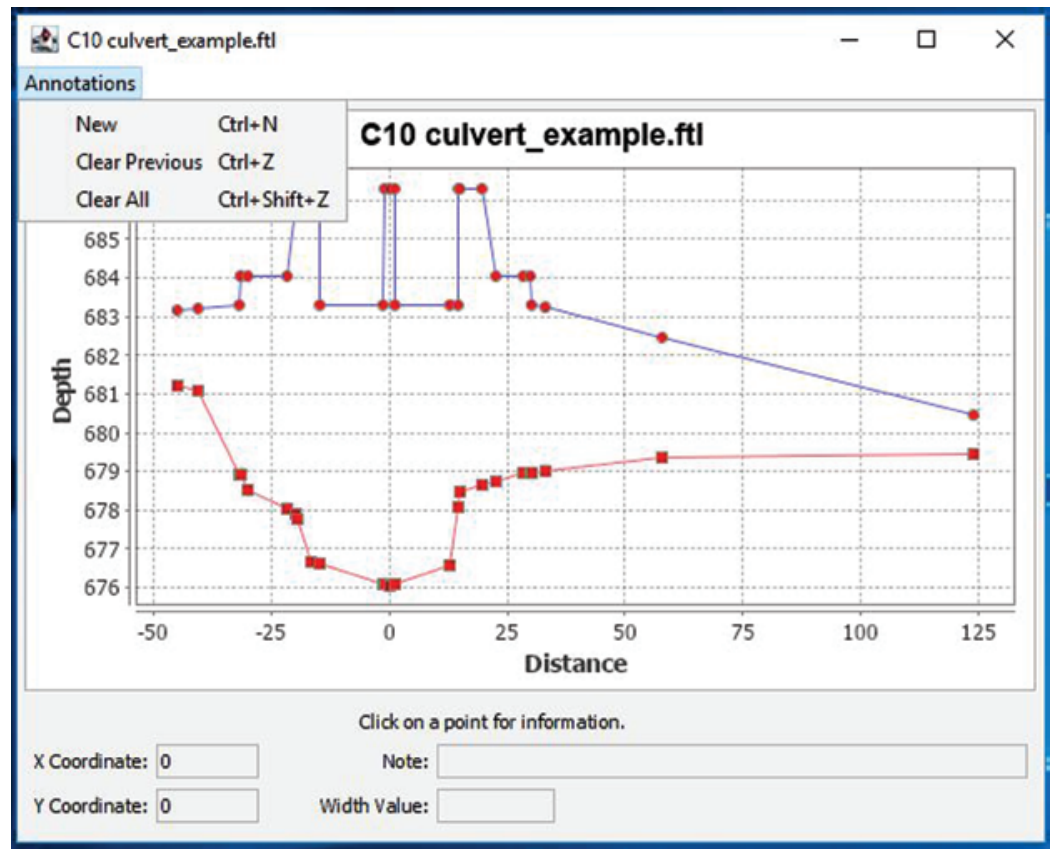

B

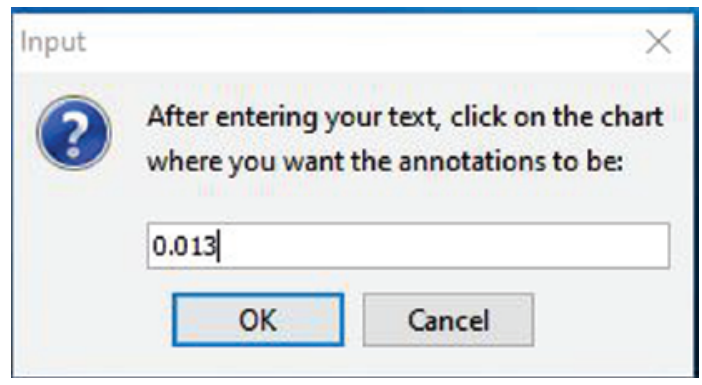

Figure 8. Screenshots showing, $A$, the Annotations drop-down menu and, $B$, text entered for new annotation. 


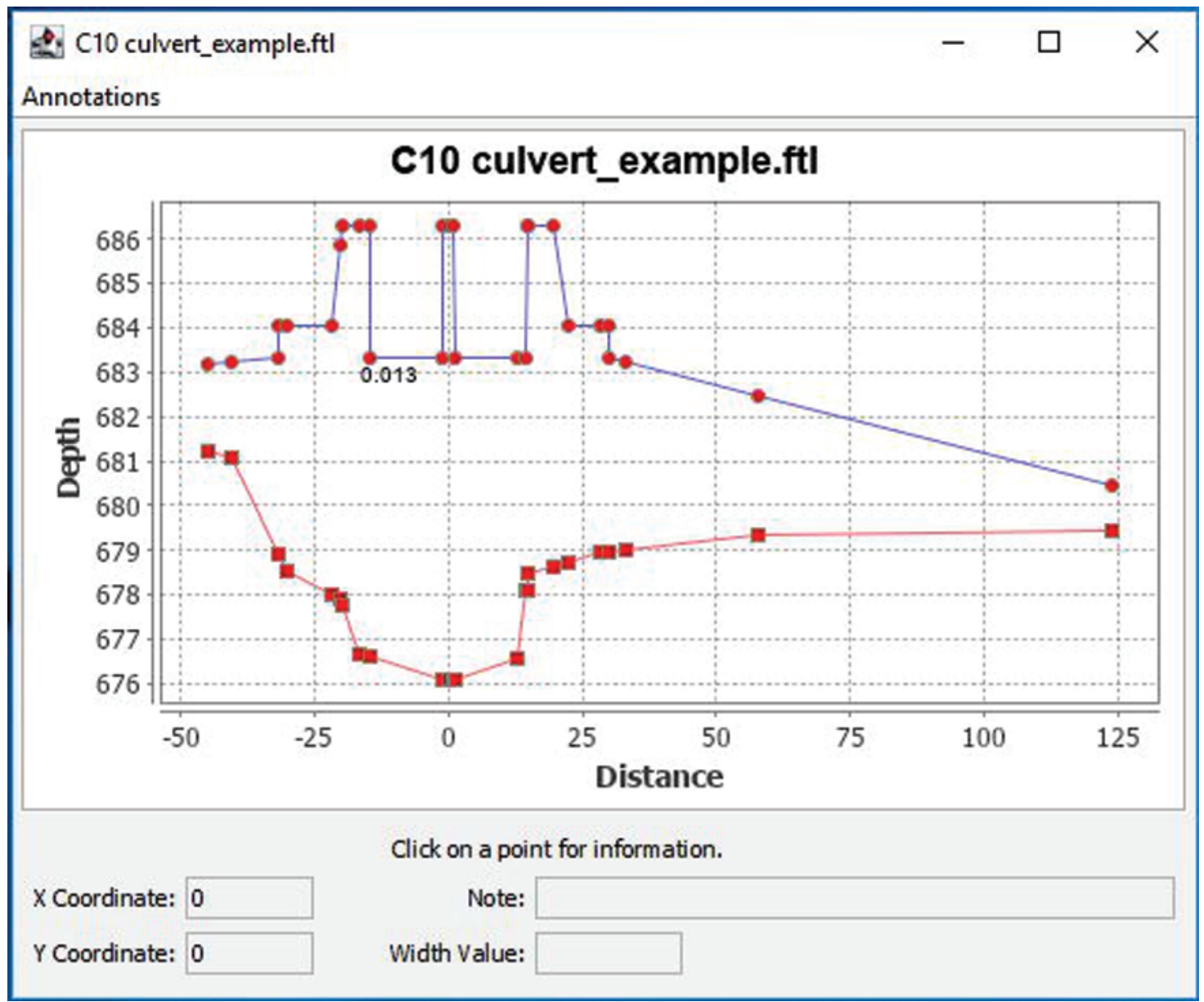

Figure 9. Screenshot showing new annotation on the chart.

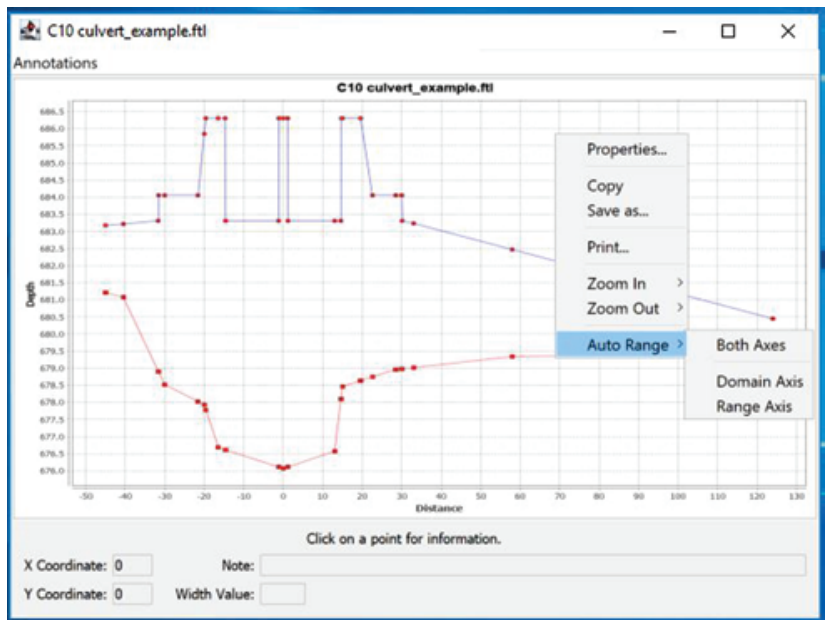

Figure 10. Screenshot showing the context menu.

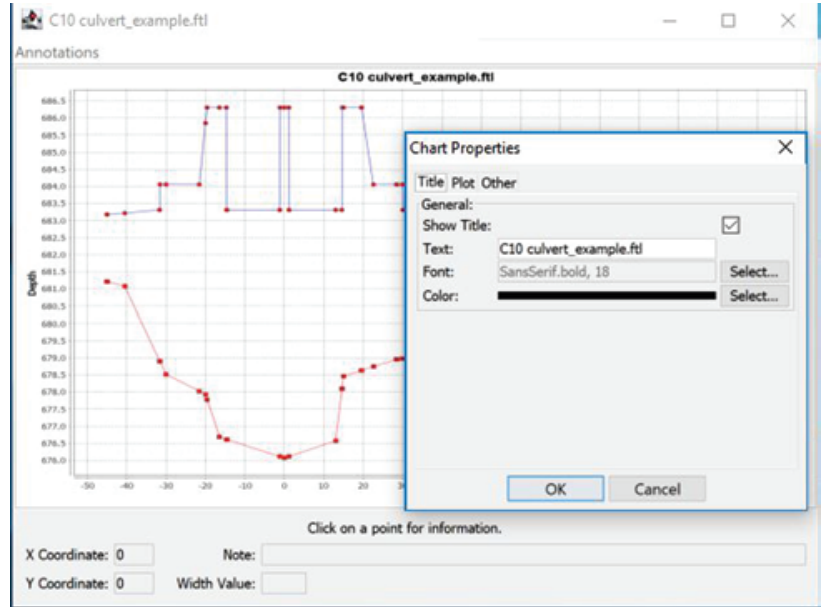

Figure 11. Screenshot showing the Chart Properties menu. 
For more information about this publication, contact:

Director, USGS Central Midwest Water Science Center

405 North Goodwin

Urbana, IL 61801

217-328-8747

For additional information, visit: https://www.usgs.gov/centers/cmwater

Publishing support provided by the

Rolla Publishing Service Center 



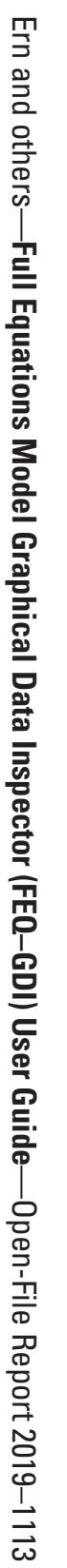

